\title{
The Prevalence of Foot Structural Deformities in Female Hairdressers Working in Shiraz
}

Tahere Rezaeian $^{1 *}$, Tahere Motiallah ${ }^{1}$, Najme Ghanbari $^{1}$, Fahime Moghimi ${ }^{2}$, Soraya Piroozi ${ }^{1}$

2. Department of Physiotherapy, School of Rehabilitation Sciences, Shiraz University of Medical Sciences, Shiraz, Iran

Citation: Rezaeian T, Motiallah T, Ghanbari N, Moghimi F, Piroozi S. The prevalence of foot structural deformities in female hairdressers working in Shiraz. Physical Therapy. 2015; 5(2):73-82. http://dx.crossref.org/10.15412/J.PTJ.07050202

: http://dx.crossref.org/10.15412/J.PTJ.07050202

Article info:

Received: 18 Jan. 2015

Accepted: 01 May 2015

Keywords:

Female, Hair, Pain, Foot, Deformity

\begin{abstract}
A B S T RA C T
Purpose: The prevalence of work-related musculoskeletal disorders is increasing worldwide. This research surveys the prevalence of pain among female hairdressers in Shiraz in 2010.

Methods: This is a survey study and a total number of 239 hairdressers were selected in Shiraz, Iran by available sampling method. Data were collected by interview and filling out questionnaires about their age, body mass index (BMI), marital status, work experience, total work time, positions during work, types of shoes worn during work, and use of arch support. Also, different diseases such as hallux valgus, hallux rigidus, turf toe, hammer toe, arch foot, plantar fasciitis, posterior tarsal tunnel syndrome, metatarsalgia, metatarsal neuralgia, and cuboid syndrome were evaluated among them. Collected data were analyzed by descriptive statistics and the Chi-square test through SPSS software (version 16) to estimate the prevalence of pain and structural disorders among hairdressers.
\end{abstract}

Results: The results showed that $30.1 \%$ of subjects had a BMI lower than 18 and $56.1 \%$ of them were married. Also $38.9 \%$ of subjects worked more than 8 hours per day and $69.5 \%$ of them worked in the standing position. According to the results, $53.1 \%$ of the subjects worn ordinary sandals and only $8.4 \%$ of them used arch support. Hallux valgus was found as a common deformity (54.9\%) among study subjects, also $34.8 \%$ of them had hallux rigidus and $31 \%$ calf pain and metatarsalgia. The result also revealed a significant correlation between prevalence of structural deformity and variables of BMI, marital status, total work time per day, work experience, use of arch support, and type of shoes worn during the work.

Conclusion: Several factors can cause discomfort in the legs and feet in hairdressers. Therefore, hairdressers should be trained in correct work procedures. Furthermore, modifying work conditions such as designing a proper chair, reducing working hours, and using medical shoes and sandals can reduce the prevalence of musculoskeletal disorders in this occupational group.

\footnotetext{
* Corresponding Author:

Tahere Rezaeian, PhD Student

Address: Department of Physiotherapy, School of Rehabilitation Sciences, Shiraz University of Medical Sciences, Shiraz, Iran

Phone: +98 (910) 7031028

E-mail: tahere.rezaiyan@gmail.com
} 


\section{Introduction}

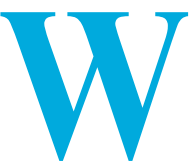

orking is among the factors which, to a great extent, affects the health and development of a society in terms of social and economic aspects. Working environment and conditions might cause a number of physical disorders or maladies related to work, thereby reducing the work efficiency $[1,2]$. In the modern world, due to a wide range of jobs, the number of musculoskeletal disorders is ever increasing. The researchers in developed countries have collected valuable information regarding the relationship between professional activities and musculoskeletal disorders. Likewise, the researchers in developing countries report more or less the same data concerning this problem $[3,4]$.

This matter was also investigated in the present study. Musculoskeletal disorders attributed to work usually involve waist, spinal column, and upper limbs. These disorders are the most common job-related complaints and thereby are the most contributing factor to workers' inability to work. Musculoskeletal diseases comprised $7 \%$ of community patients, $14 \%$ of referring physicians, and $19 \%$ of hospital admissions. About $62 \%$ of patients with musculoskeletal diseases have limitation of movements [5].

Various risk factors play significant roles in causing such harms. These risks can be divided into physical risk factors, including poor posture, lifting and carrying heavy loads, repetitive movements, as well as psychological, organizational, and individual activities $[6,7]$. Working in hard and unpleasant conditions causes temporary discomfort in the whole body and in case of continuing such circumstances, permanent malady and discomfort will develop in musculoskeletal or nervous system. As a result, it will lead to inability to work. Also, the main complaint of those who constantly work in standing position would be pain in feet and lower parts of the body [8].

One of the jobs which causes musculoskeletal disorder is hairdressing. This job involves doing a specific activity, either in standing or sitting position for a long time. In the former case, the whole weight is distributed on the legs and feet, causing disorders in this area. However, the latter leads to pain in back and waist. In hairdressing, due to repetitive movements, prolonged working in standing or even wrong positions and postures may cause musculoskeletal disorders. Preventing such diseases requires body position analysis using professional methods of ergonomics so that modifications be applied whenever needed [9].
In a study by Margaret Best conducted on 204 hairdressers in Australia in 2014, 70\% of them suffered from musculoskeletal disorders and discomforts in different parts of the body. Also, it was pointed out that long stand-up and wrong working postures were among the leading factors causing these problems [10].

In a study by Nasir et al. in 1988 in Tehran University of Medical Sciences, the job-related problems such as dermatologic disorders, respiratory diseases, osteoarthritis, and varicose veins were studied among the hairdressers in Tehran. The study subjects comprised 598 hairdressers, (200 females and 398 males) all chosen randomly from different areas of Tehran. The results showed the widespread epidemics of dermatologic disorders $(22.24 \%)$, yet the number of those suffering from osteoarthritis was remarkably higher. As suggested by the gathered data, 133 had dermatologic disorders, 213 had varicose veins, and 517 suffered from osteoarthritis. Of them, 333 (105 females and 228 males) complained from pain in their legs and calves. Only $13.8 \%$ showed any signs and symptoms of respiratory disorders [11].

Warren Glover and colleagues in a study conducted in 2005 in London, evaluated the prevalence of musculoskeletal disorders in the physiotherapy community members. A total of 3661 subjects were randomly collected using a questionnaire. The results showed that disorders of the spine, which includes symptoms of neck, lumbar, and thoracic areas, were prevalent among physiotherapists. So that $69 \%$ of them reported serious symptoms in these areas. In contrast, only $25 \%$ and $5 \%$ of them complained from upper and lower extremity pain, resectively [12]

A study in Taiwan compared the mechanical coping of barbers' and hairdressers' wrists upon trimming and cutting. It yielded that the average time served for a female client (51.4 minutes) was significantly longer than a male client (35.6 minutes) and electrical activities of muscles were more in women than men. Given that few studies have been done in this area, information related to musculoskeletal problems in this occupational group is not enough [13].

The main objective of the present study was to study the widespread epidemics of such structural deformities among female hairdressers in Shiraz, Iran avoiding any limitations with regard to region or whatsoever. In the study based on questionnaire, structural deformities in legs and feet of the subjects were studied so as to elucidate the fact that if their different postures and positions while working could cause musculoskeletal problems. Furthermore, the possible effects of using insoles 
in shoes in preventing or alleviating pain and structural deformities were studied.

\section{Materials and Methods}

This study is an epidemiological survey. A total of 239 hairdressers were selected for the study by convenient sampling method from all city areas. The research setting was the subjects' own business locations. The samples comprised all age groups. Inclusion criteria included their willingness to participate in research and working as a hairdresser or a barber in Shiraz. The exclusion criteria were having congenital abnormalities, fractures in knees or feet, diabetes, and pregnancy. To collect data a questionnaire, consisting of 2 parts was used. The first part included questions about personal and professional characteristics such as age, body mass index (BMI), marital status, work experience, working hours, type of footwear when working and using insoles in shoes. The second part included questions about having any foot deformity such as hallux valgus, hallux rigidus, turf toe, arch foot, plantar fasciitis, calf pain, posterior tarsal tunnel syndrome, metatarsalgia, metatarsal neuralgia, and cuboid syndrome.

BMI was obtained through calculating the ratio of weight to height. The subject's height was measured using meter scale and multiplied by itself followed by calculating weight in kilos and dividing them by the multiplication gained previously. The resulting figure is called BMI that is reported in kilograms per square meters. The numerical value of the index based on Quetelet Index is classified as follows:

- Very thin individuals with obesity index lower than or equal to 20.29 ,
- Thin individuals with obesity index from 20.30 to 22.29 ,

- Average individuals with obesity index from 22.30 to 24.29 ,

- Fat individuals with obesity index from 24.30 to 26.99 , and

- Very fat individuals with obesity index higher than or equal to 2.100 .

The information gathered through the questionnaires was analyzed using SPSS version 16 and methods of descriptive statistics and The Chi-square test were used.

\section{Results}

The results showed that $56.1 \%$ of the subjects were married and $43.9 \%$ were single. Also, $64.9 \%$ of the subjects were in the age group of $25-35$ years. About $30.16 \%$ were in the "very thin" classification with the BMI (Table 1). The results indicated that the largest number of people $(40.2 \%)$ had the working experience of lower than or equal to 5 years. About $38.9 \%$ worked over 8 hours a day, $53.1 \%$ used usual sandal while working and $91.6 \%$ used no insoles in their shoes (Table 2). Of 239 female hairdressers, $54.9 \%$ had hallux valgus, $34.8 \%$ hallux rigidus, $8.8 \%$ turf toe, $1.6 \%$ hammer toe, $18.2 \%$ plantar fasciitis, $31 \%$ calf pain, and $10 \%$ posterior tarsal tunnel syndrome. Also, $31 \%$ of them had metatarsalgia, $17.9 \%$ metatarsal neuralgia, and $8.5 \%$ cuboid syndrome (Table 3 ).

Regarding the relationship between the hallux rigidus and BMI, the results showed that $30.6 \%$ of the first group, $45.7 \%$ of the second group, $45.2 \%$ of the third

Table 1. Study subjects' age groups, BMI, and marital status.

\begin{tabular}{|c|c|c|c|}
\hline Variables & Numbers and percentages & No. & $\%$ \\
\hline \multirow{3}{*}{ Age group } & $25-35$ years & 155 & 64.9 \\
\hline & $36-45$ years & 62 & 25.9 \\
\hline & $46-55$ years & 22 & 9.2 \\
\hline \multirow{5}{*}{ BMI } & Very thin & 72 & 30.1 \\
\hline & Thin & 35 & 14.6 \\
\hline & Average & 42 & 17.6 \\
\hline & Obese & 35 & 14.6 \\
\hline & Very obese & 55 & 23 \\
\hline \multirow{2}{*}{ Marital status } & Married & 134 & 56.1 \\
\hline & Single & 105 & 43.9 \\
\hline
\end{tabular}


Table 2. Study subjects' work experience, working hours, and wearing shoes with or without insoles.

\begin{tabular}{|c|c|c|c|c|}
\hline & & percentages & No. & $\%$ \\
\hline \multirow{4}{*}{ Work experience, $Y$} & $\leq 5$ & & 96 & 40.2 \\
\hline & $6-10$ & & 86 & 36 \\
\hline & $11-15$ & & 30 & 12.6 \\
\hline & $>15$ & & 27 & 11.3 \\
\hline \multirow{3}{*}{ Working hours } & $<8$ & & 78 & 32.6 \\
\hline & 8 & & 68 & 28.5 \\
\hline & $>8$ & & 93 & 38.9 \\
\hline \multirow{4}{*}{ Type of working shoes } & \multirow{2}{*}{ Shoes } & Usual & 52 & 21.8 \\
\hline & & Medical & 15 & 6.3 \\
\hline & \multirow{2}{*}{ Sandal } & Usual & 127 & 53.1 \\
\hline & & Medical & 45 & 18.8 \\
\hline \multirow{2}{*}{ Insoles in shoes } & Yes & & 20 & 8.4 \\
\hline & No & & 219 & 91.6 \\
\hline
\end{tabular}

PHYSICAL TREA TMENTS

group, $60 \%$ of the fourth and $60 \%$ of the fifth group had hallux rigidus (Table 4$)$. These findings were statistically significant $(\mathrm{P}=0.03)$. Regarding the relationship between turf toe and BMI, it was found that $15.3 \%$ of the first group, $11.4 \%$ of the second group, $7.1 \%$ of the third group, $14.3 \%$ of fourth group, and $9.1 \%$ of the fifth group had turf toe (Table 4). These results were statistically significant, too $(\mathrm{P}=0.03)$. Finally, regarding the relationship between the metatarsalgia and BMI, 31.9\% of the first group, $34.3 \%$ of the second group, $33.3 \%$ of the third group, $62.9 \%$ of the fourth group, and $78.2 \%$ of the fifth group complained from metatarsalgia. These findings were statistically significant $(\mathrm{P}=0.01)$ (Table 4).

Regarding the relationship between plantar fasciitis and marital status, it was found that $29.9 \%$ of married couples and $17.1 \%$ of single people had plantar fasciitis. These findings were statistically significant $(\mathrm{P}=0.02)$ (Table 5).

Regarding the relationship between the hallux rigidus and working experience, it was found that $54.2 \%$ of the first group, $37.2 \%$ of the second group $30 \%$ of the third group, and $66.7 \%$ of the fourth group had hallux rigidus

Table 3. Study subjects' foot structural deformity.

\begin{tabular}{|cccc}
\hline Nariables & No. & \% \\
\hline Hallux valgus & 175 & 54.9 \\
\hline Hallux rigidus & 111 & 43.8 \\
\hline Turf toe & 28 & 8.8 \\
\hline Hammer toe & 5 & 1.6 \\
\hline Supinated foot & 16 & 5 \\
\hline Pronated foot & 126 & 39.5 \\
\hline Plantar fasciitis & 58 & 18.2 \\
\hline Calf pain & 99 & 31 \\
\hline Posterior tarsal tunnel syndrome & 32 & 10 \\
\hline Metatarsalgia & 99 & 31 \\
\hline Metatarsal neuralgia & 57 & 17.9 \\
\hline Cuboid syndrome & 27 & 8.5 \\
\hline
\end{tabular}




\section{mit}

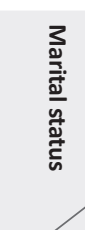

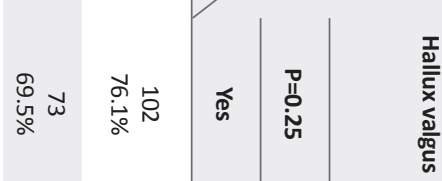

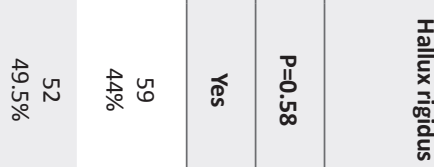

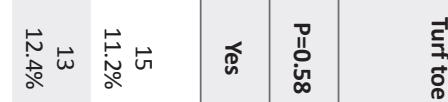

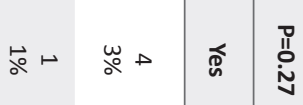

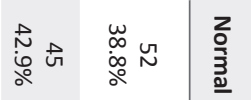

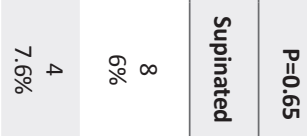

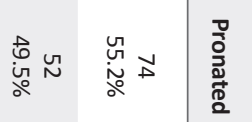

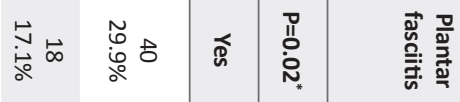

永屯嘉出

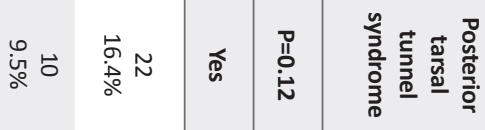

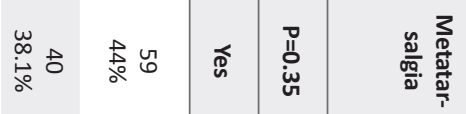

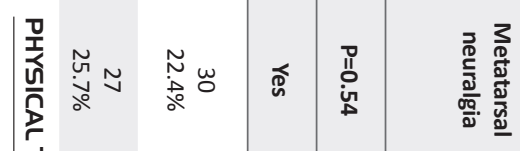

离

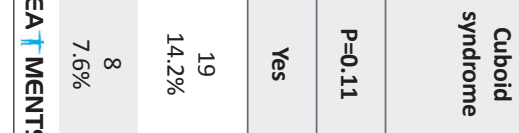

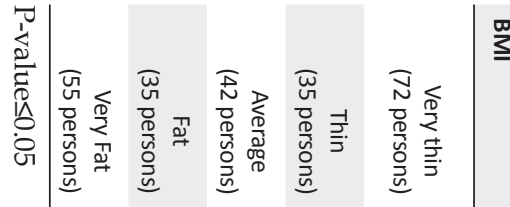

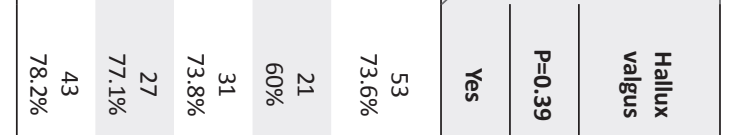

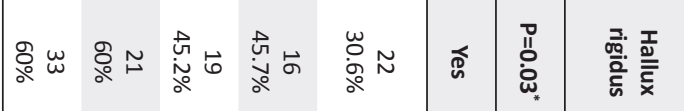

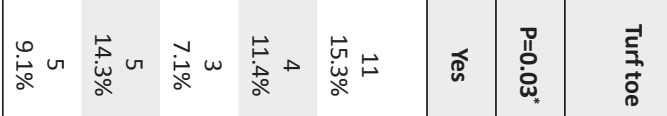

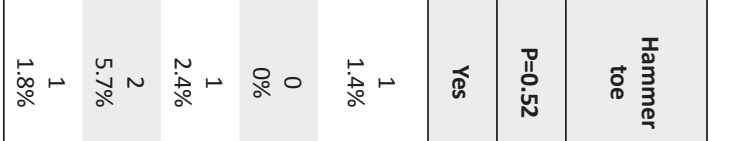

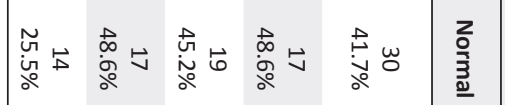

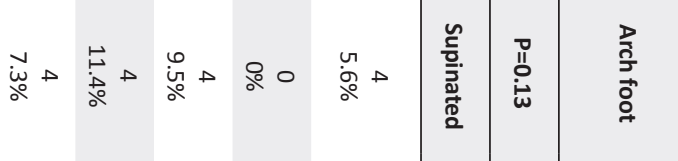

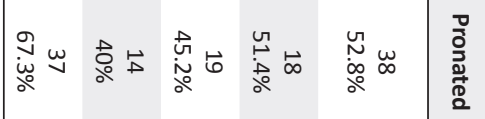

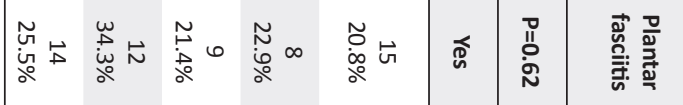

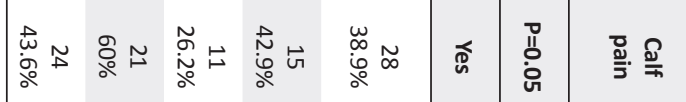

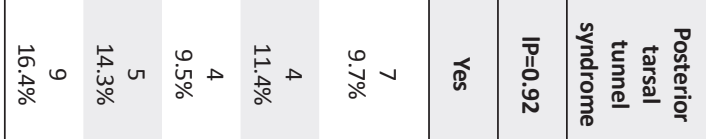

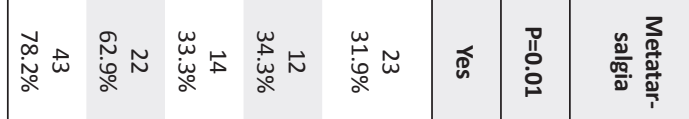

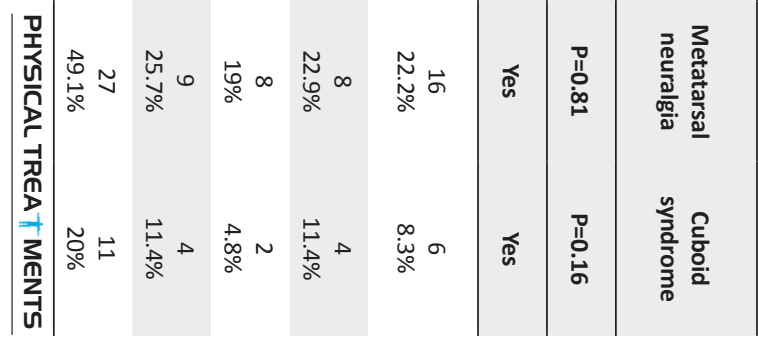



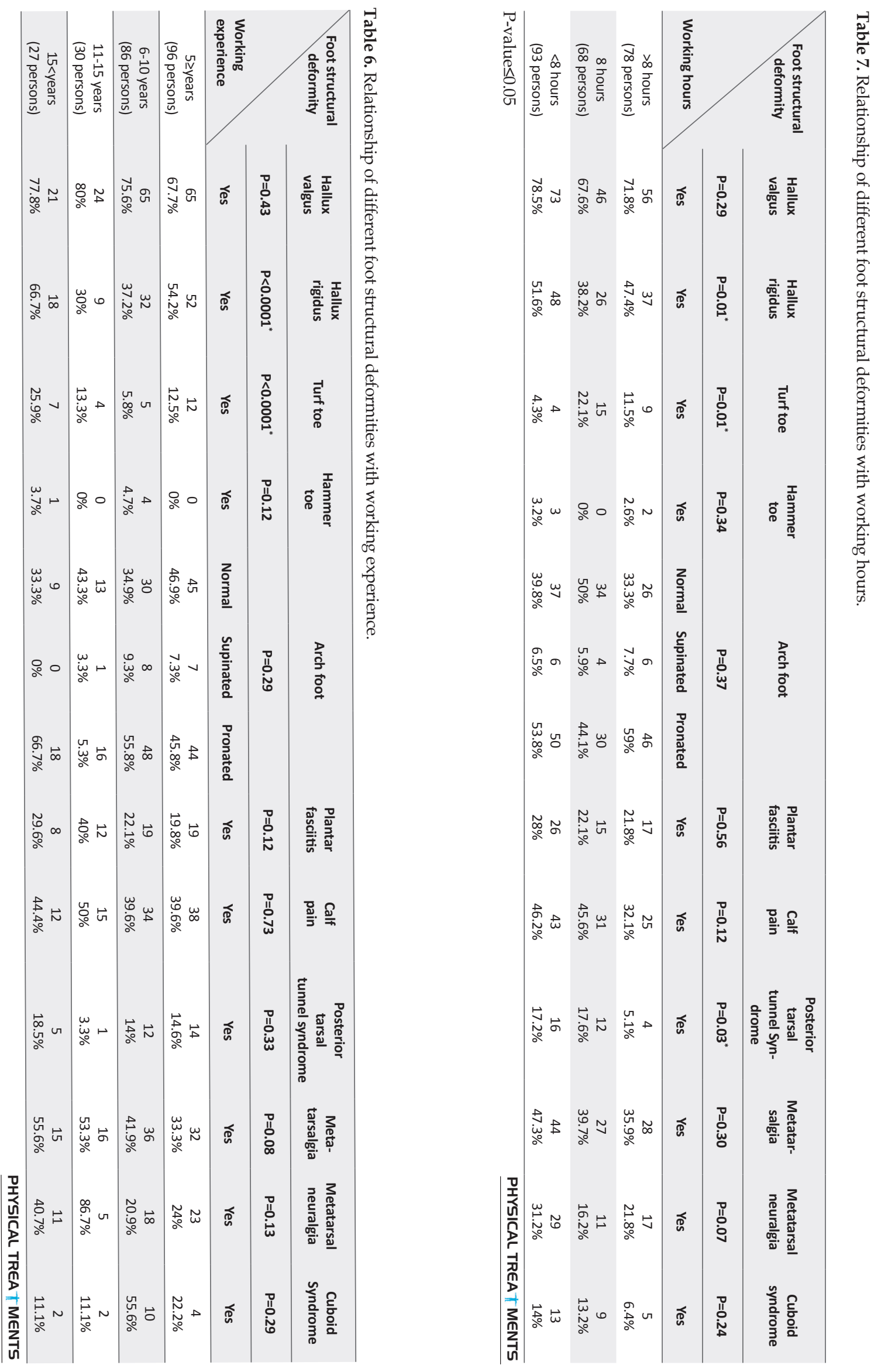

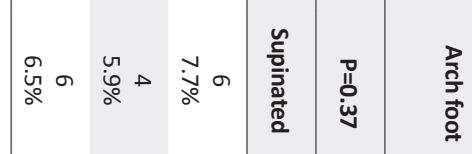

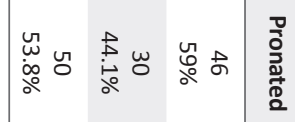

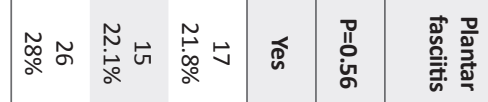

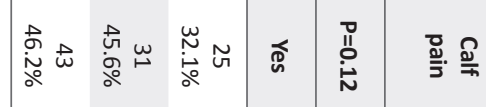

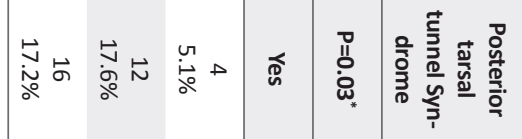

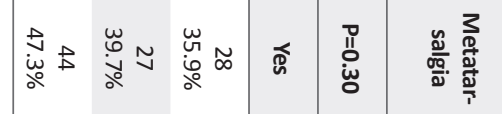

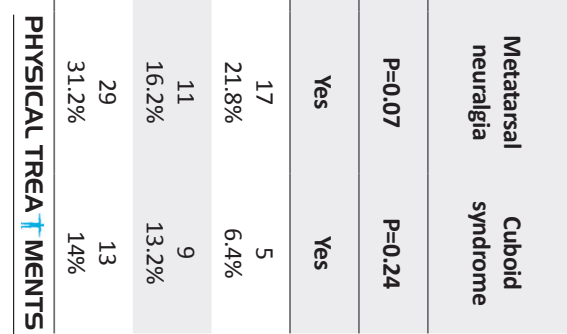



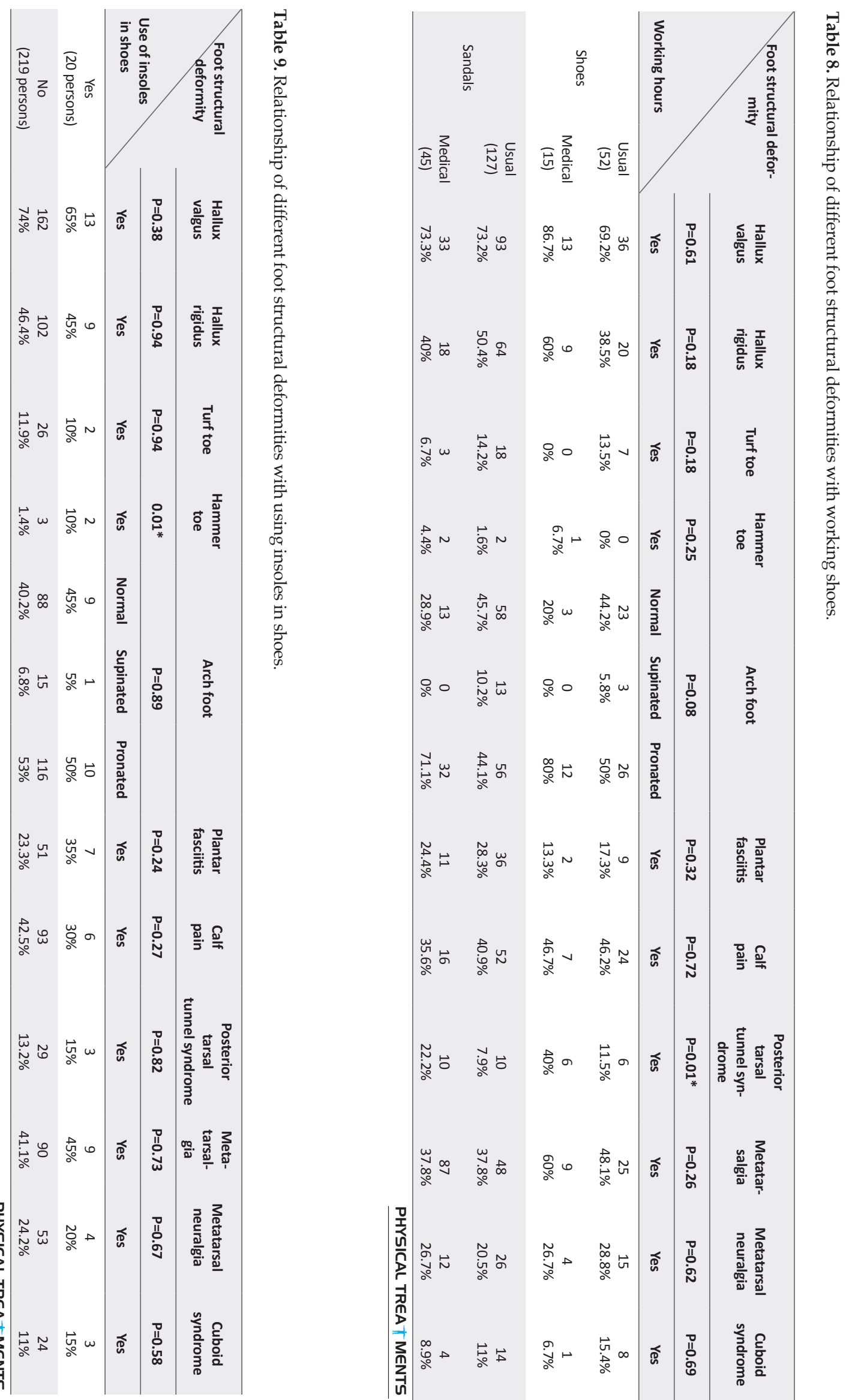

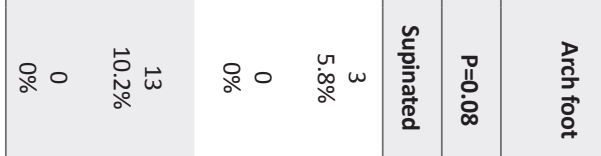
苞岕

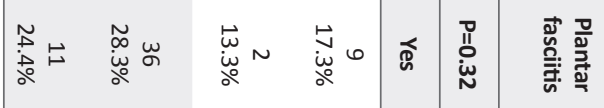

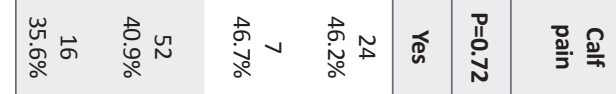

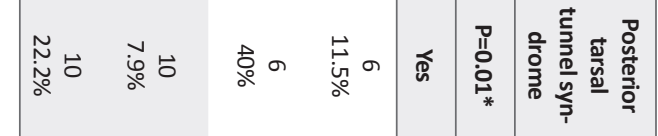

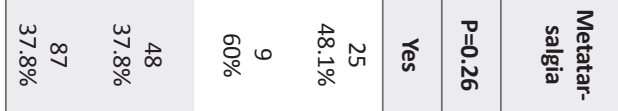

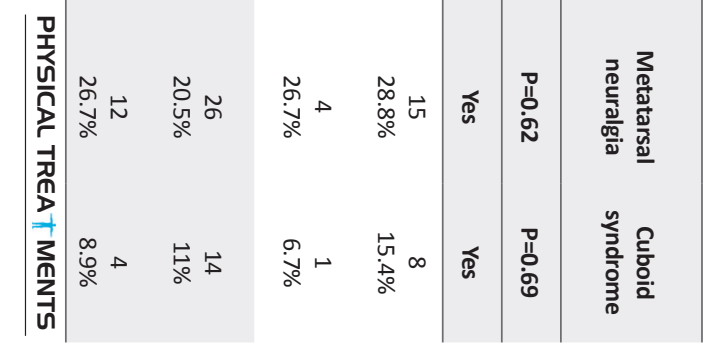


(Table 6). These findings were statistically significant $(\mathrm{P}<0.001)$. Also, regarding the relationship between the turf toe and working experience, $12.5 \%$ of the first group, $5.8 \%$ of the second group, $13.3 \%$ of the third group, and $25.9 \%$ of fourth had turf toe (Table 6 ). These results were statistically significant $(\mathrm{P}<0.001)$. Finally, with regard to the relationship between hammer toe and working experience, the results showed that $4 \%$ of the second group and $3.7 \%$ of the forth group had hammer toe deformity, but this was not observed in the first and third groups (Table 6). These findings were statistically significant $(\mathrm{P}<0.001)$.

Regarding the relationship between hallux rigidus and working hours, it was found that $47.4 \%$ of the first group and $38.2 \%$ the second group and $51.6 \%$ of the third group had hallux rigidus (Table 7). These findings were statistically significant. $(\mathrm{P}=0.01)$. Also, regarding the relationship between turf toe and working hours, we found that $11.5 \%$ of the first group and $22.1 \%$ of the second group, and $4.3 \%$ of the third group had turf toe. These results were also statistically significant $(\mathrm{P}=0.01)$ (Table 7$)$.

Regarding the relationship between the posterior tarsal tunnel syndrome and type of working shoes, it was determined that $11.5 \%$ of the first group and $40 \%$ of the second group, and $7.9 \%$ of the third group and $22.2 \%$ of the fourth group had this syndrome which was statistically significant findings $(\mathrm{P}=0.01)$ (Table 8$)$.

Regarding the relationship between hammer toe and use of insoles in shoes, it was found that $10 \%$ of the first group and $1.4 \%$ of the second group had hammer toe. These findings were statistically significant $(\mathrm{P}=0.01)$ (Table 9).

\section{Discussion}

Findings of this study showed that among 239 studied female hairdressers, most of them $(54.9 \%)$ had hallux valgus. The prevalence of leg pain was $31 \%$. These findings were consistent with the results of Nasir et al. on 598 female and male hairdressers and barbers. They reported that most study participants complained from pain in their feet and calves [11]. In a study on 150 barbers, by Miri et al. in Birjand, $69 \%$ of them had discomfort in their calves [9]. Also, Hokmabadi and colleagues in a study in Esfarāyen, reported that the majority of reported complaints were pain in calves, so that $84 \%$ of participants suffered from leg pain in the last year [8].

The above results indicate that hairdressing is one of the high-risk jobs which causes pain and the structural deformities in the feet and legs. There was no signifi- cant relationship between age groups and the structural deformities. Perhaps one of the reasons was that most people were in the age range of 25-35 years and a few were in the higher age range. The results indicated that there was a significant association between the presence of structural problems and working hours and work experience so that people who were working more hours or had more work experience reported more pain and structural problems.

The results showed that by increasing the working hours, deformities such as hallux valgus, hallux rigidus, turf toe, and leg pain increases. The association between working hours per day with discomfort in the feet and legs were consistent with studies of Miri [9]. Also, Waren Glover et al. in London showed that working in a constant position for long hours, insufficient relaxation, and serving a large number of clients per day could be harm factors for different parts of body like lower parts and waist [12].

Another study revealed that the health status of the barbers and hairdressers who had their own businesses was lower than their counterparts who were paid by the others as employers. This could be attributed to some factors such as working environment and organization, long working hours, fewer security measures, and lack of preventive medical measures in work place due to poor training [14]. According to the results, a significant relationship exist between feet structural deformity and BMI so that higher BMI was associated with more structural problems in the feet such as metatarsalgia, hallux rigidus, and flat foot.

The results of the study conducted by Alexander Sigonia (2009) were nearly the same as the ones in the present study, i.e. according to them, BMI was important in knee pains [15]. There was a significant relationship between pain, foot structural deformity, and marital status. The married subjects had more pain and foot deformity such as plantar fasciitis than single ones. This might be due to the fact that married people spend less time doing exercises. According to a study by Lindal Stradine and Gabriel Bamer on female employees, the women, particularly married ones, due to doing house chores, caring children, and lack of time to spend on relaxation and not doing exercises, were more likely to be exposed to harms [16].

There was a significant relationship between foot structural deformity and type of working shoes so that people who used shoes suffered more from tarsal tunnel syndrome than those who had used sandals. Therefore, using medical sandals could reduce the pain in these in- 
dividuals. Also, a significant correlation exists between foot structural deformities such as hammer toe and using the insole inside the shoes. So that people who wore insoles inside their shoes reported less problems. Rezaeian and her colleagues showed that a significant relation was noticed between pain intensity and type of shoes worn while working [17].

The limitations of this research was insufficient cooperation of female hairdressers union of Shiraz in providing the names and phone numbers of hairdressers and refusal to introduce a visit to the hairdresser, also lack of cooperation due to the workload and the distribution of hair salons in Shiraz.

According to the findings of the study, a variety of factors could result in pain in feet and calves. Therefore, it is recommended that hairdressers were trained in correct work procedures. Also modifying work conditions such as designing a proper chair, using soft pillows beneath feet, reducing working hours, and using medical shoes and sandals can reduce the incidence of musculoskeletal disorders in this occupational group.

\section{Acknowledgements}

The article is supported by Shiraz Univesity of Medical Sciences, Shiraz, Iran.

\section{Conflict of Interests}

The authors declared no conflict of interests.

\section{Reference:}

[1] Richardson SM, Hoyland JA. Stem cell regeneration of degenerated intervertebral discs: current status. Current Pain and Headache Reports. 2008; 12(2):83-88.

[2] Mohseni Bandpey MA, Ahmadshirvani M, Bagheri M, Khalilian A. [A pathological investigation of back pain in nurse (Persian)]. Journal of Babol University of Medical Sciences. 2004; 2(26):35-41.

[3] Smith DR, Sato M, Miyajima T, Mizutani T, Yamagata Z. Musculoskeletal disorders self-reported by female nursing students in central Japan: a complete cross-sectional survey. International Journal of Nursing Studies. 2003; 40(7):725-29.

[4] Maul I, Läubli T, Klipstein A, Krueger H. Course of low back pain among nurses: a longitudinal study across eight years. Occupational and Environmental Medicine. 2003; 60(7):497-503.

[5] AghiliNejad M, Farshad AA, Mostafaei M, Ghafari M. [Occupational Medicine Practice (Persian)]. Tehran: Arjmand Publication; 2001.
[6] Kee D, Karwowski W. LUBA: an assessment technique for postural loading on the upper body based on joint motion discomfort and maximum holding time. Applied Ergonomics. 2001; 32(4):357-66.

[7] Mirmohamadi M, Nasl Seraji J, Shahtaheri J, Lahmi M, Ghasemkhani M. Evaluation of risk factors causing musculoskeletal disorders using QEC method in a furniture producing unite. Iranian Journal of Public Health. 2004; 33(2):24-27.

[8] Hokmabadi RA, Halvani GH, Fallah H. [Ergonomic principles decuple (Persian)]. Tehran: Asar Sobhan Press; 2014,

[9] Miri MR, Hosseini M, Sharifzadeh G. [Evaluation of ergonomic postures of hairdressers by REBA in Birjand (Persian)]. Horizon of Medical Sciences. 2008; 14(2):39-44.

[10] Best M, French G, Ciantar JP, Didzys DG, Fitzgerald CM, Moore KR, et al. Work-related musculoskeletal disorders in hairdressers. Journal of Occupational Health. 2002; 18:67-76.

[11] Mahmoudi F. Occupational health problems of hairdressers of Tehran. Acta Medica Iranica. 1996; 34(1-2):14-16.

[12] Glover W, McGregor A, Sullivan C, Hague J. Work-related musculoskeletal disorders affecting members of the Chartered Society of Physiotherapy. Physiotherapy. 2005; 91(3):138-47.

[13] Chen HC, Chang CM, Liu YP, Chen CY. Ergonomic risk factors for the wrists of hairdressers. Applied Ergonomics. 2010; 41(1):98-105.

[14] Deschamps F, Langrand J, Lesage FX. Health assessment of self-employed hairdressers in France. Journal of Occupational Health. 2014; 56(2):157-63.

[15] Tsigonia A, Tanagra D, Linos A, Merekoulias G, Alexopoulos EC. Musculoskeletal disorders among cosmetologists. International Journal of Environmental Research and Public Health. 2009; 6(12):2967-979.

[16] Strazdins L, Bammer G. Women, work and musculoskeletal health. Social Science \& Medicine. 2004; 58(6):997-1005

[17] Rezaeian T, Piroozi S, Ghanbari N, Moghimi F, Motiallah T. The Prevalence of Leg Pain among Female Hairdressers: A Case Study in Shiraz in 2010. Physical Treatments-Specific Physical Therapy Journal. 2015; 5(1):33-40. 
